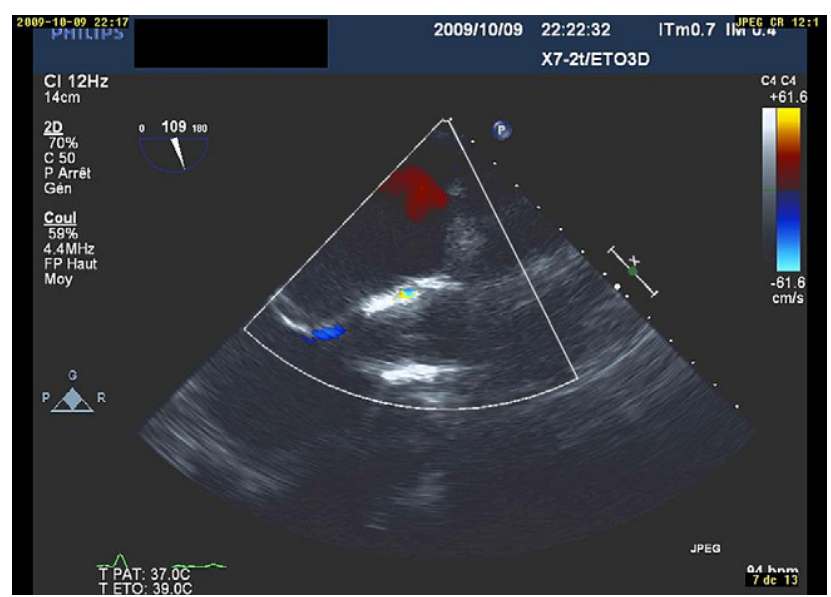

FIGURE 2. Valve-in-valve placement.

feasibility. A major concern is retraumatizing the LV apex, with consequent tearing and hemorrhage. Although we at- tained adequate hemostasis using conventional techniques, we would urge others to select and expose access vessels for CPB should it be urgently required during the procedure.

\section{References}

1. Vahanian A, Alfieri OR, Al-Attar N, Antunes MJ, Bax J, Cormier B, et al. Transcatheter valve implantation for patients with aortic stenosis: a position statement from the European Association of Cardio-Thoracic Surgery (EACTS) and the European Society of Cardiology (ESC), in collaboration with the European Association of Percutaneous Cardiovascular Interventions (EAPCI). Eur J Cardiothorac Surg. 2008;34:1-8.

2. Rodés-Cabau J, Webb JG, Cheung A, Ye J, Dumont E, Feindel CM, et al. Transcatheter aortic valve implantation for the treatment of severe symptomatic aortic stenosis in patients at very high or prohibitive surgical risk. Acute and late outcomes of the multicenter Canadian experience. J Am Coll Cardiol. 2010;55: 1080-90.

3. Walther T, Dewey T, Borger MA, Kempfert J, Linke A, Becht R, et al. Transapical aortic valve implantation: step by step. Ann Thorac Surg. 2009;87:276-83.

4. Rodés-Cabau J, Dumont E, Doyle D. "Valve-in-valve" for the treatment of paravalvular leaks following transcatheter aortic valve implantation. Catheter Cardiovasc Interv. 2009;74:1116-9.

\title{
A combined procedure of thoracoabdominal aortic aneurysm repair and coronary artery bypass grafting: Report of two cases
}

\author{
Saina Attaran, MRCS, Mark Field, FRCS, Manoj Kuduvalli, FRCS, and Aung Oo, FRCS, Liverpool, \\ United Kingdom
}

The prevalence of coronary artery disease in patients with aneurysm of the aorta is $40 \%$ to $60 \%{ }^{1,2}$ Coronary artery disease is a significant predictor of early mortality after aneurysm repair. ${ }^{3,4}$ Therefore, coronary artery revascularization before the repair of aneurysms is recommended but carries a $10 \%$ risk of perioperative aneurysm rupture. ${ }^{5}$ Moreover, a 2 -staged approach will leave the patient with 2 scars, twice the hospitalizations, and an increase in interval delays.

We describe a successful combined procedure of thoracoabdominal aortic aneurysm (TAAA) repair and coronary artery bypass grafting (CABG) performed in 2 cases.

\footnotetext{
From the Thoracic Aortic Aneurysm Service, Liverpool Heart and Chest Hospital, Liverpool, United Kingdom.

Disclosures: Authors have nothing to disclose with regard to commercial support.

Received for publication Feb 8, 2010; revisions received June 23, 2010; accepted for publication July 12, 2010; available ahead of print Aug 30, 2010.

Address for reprints: Saina Attaran, MRCS, Liverpool Heart and Chest Hospital NHS Foundation Trust, Thomas Dr, Liverpool, L14 3PE, United Kingdom (E-mail: saina.attaran@kcl.ac.uk)

J Thorac Cardiovasc Surg 2011;141:1078-9

0022-5223/\$36.00

Copyright (C) 2011 by The American Association for Thoracic Surgery

doi:10.1016/j.jtcvs.2010.07.022
}

\section{CLINICAL SUMMARY \\ Patient 1}

A 64-year-old man who presented with back pain underwent a computed tomographic (CT) scan that confirmed a contained rupture of a Crawford extent II TAAA $(6.5 \mathrm{~cm})$. He also had a significant history of angina. Coronary angiogram showed a severe segment of stenoses in the circumflex artery and an unstable plaque in the dominant right coronary artery. The possibility of percutaneous intervention was discussed with the cardiologists; the coronary anatomy was considered not suitable for this treatment.

\section{Patient 2}

A 64-year-old man with history of myocardial infarction and recent angina was known to have a Crawford extent II TAAA aneurysm $(11.5 \mathrm{~cm})$. The angiogram demonstrated an occluded left anterior descending artery, but stress magnetic resonance imaging revealed inducible ischemia in its territory.

The sequence of treatment is controversial; we planned to perform a single-stage procedure to repair the aneurysm and revascularize the heart simultaneously. 


\section{METHODS \\ Patient 1}

With the patient in the supine position, concurrent with harvesting the long saphenous vein, an 8-mm Dacron tube graft (Meadox Medicals, Inc, Oakland, NJ) was anastomosed end to side to the right axillary artery. The conduit was clamped distally and the patient was positioned to the right lateral oblique. The Dacron tube graft was connected to the arterial cannula for inflow along with the left femoral artery. After thoracolaparotomy, the pericardium was opened. The main pulmonary artery and the left femoral vein were cannulated for venous drainage. The TAAA was exposed retroperitoneally. Cardiopulmonary bypass (CPB) was established with inflow via the right axillary artery only. With the use of an Octopus tissue stabilizer IV (Medtronic, Inc, Minneapolis, Minn), 2 lengths of the long saphenous vein were anastomosed to the posterior descending and circumflex arteries while on CPB with the heart beating.

After clamping of the aorta distal to the left subclavian artery and above the aortic bifurcation, the aneurysmal segment was replaced with a size 26-mm Hemashield Dacron tube graft (Meadox Medicals, Inc, Oakland, $\mathrm{NJ}$ ).

Owing to the heavy calcification of the ascending aorta, the vein graft to the circumflex artery was routed through an incision in the pericardium behind the phrenic nerve, over the hilum of the left lung to anastomose to the tube graft. The vein graft to the posterior descending artery was then anastomosed to the side of circumflex graft. The patient was rewarmed and weaned off CPB. Without changing his position, we decannulated and closed the scars with the patient in the right lateral position, tilting the table sideways to facilitate access to the axillary cannulation site and the groin.

\section{Patient 2}

After left thoracolaparotomy, the left internal thoracic artery was harvested. After systemic heparinization, the left internal thoracic artery was anastomosed to the left anterior descending coronary artery using the Octopus IV stabilizer. On left heart bypass via cannulae in the left inferior pulmonary vein and left femoral artery, the aneurysmal aorta was opened and replaced with a 28-mm Hemashield Dacron tube graft. Finally, visceral, renal, and one pair of lumbar arteries were implanted onto the tube graft with separate $10-\mathrm{mm}$ tube grafts. The clamps were removed and left heart bypass was terminated.

\section{RESULTS}

Two weeks postoperatively, patient 1 had moderate renal impairment (creatinine level $271 \mathrm{Umol} / \mathrm{L}$ ), and the computed tomographic scan showed an exaggeration of a pre-existing plaque lesion in the left renal artery. Stenting of the renal artery was considered, but with conservative management renal function improved. Patient 2 recovered uneventfully. They were reviewed at 6 weeks with a follow-up computed tomographic scan showing satisfactory repair of the TAAA. They are currently under 6 months' follow-up in the outpatient setting.

\section{COMMENT}

Satisfactory results with the joint procedure of abdominal aortic aneurysm repair and CABG have been reported previously. This is the first report of a combined procedure of a Crawford extent II TAAA repair and CABG. This approach is invasive but possesses several advantages: it decreases the chance of peri-CABG rupture of the aneurysm or myocardial infarction perianeurysm repair and is more convenient for the patients, inasmuch as they have to recover from a single operation. With the thoracolaparotomy incision, full exposure to the heart and the aorta is feasible and complete revascularization with or without the use of CPB can be achieved.

\section{References}

1. Hirose K, Chikamori T, Hida S, Tanaka H, Igarashi Y, Watanabe Y, et al. Prevalence of coronary heart disease in patients with aortic aneurysm and/or peripheral artery disease. Am J Cardiol. 2009;103:1215-20.

2. Ruby ST, Whittemore AD, Couch NP, Collins JJ, Cohn L, Shemin R, et al. Coronary artery disease in patients requiring abdominal aortic aneurysm repair. Selective use of a combined operation. Ann Surg. 1985;201: 758-64.

3. Kieffer E, Chiche L, Godet G, Koskas F, Bahnini A, Bertrand M, et al. Type IV thoracoabdominal aneurysm repair: predictors of postoperative mortality, spinal cord injury, and acute intestinal ischemia. Ann Vasc Surg. 2008;22: 822-8.

4. Kieffer E, Chiche L, Baron JF, Godet G, Koskas F, Bahnini A. Coronary and carotid artery disease in patients with degenerative aneurysm of the descending thoracic or thoracoabdominal aorta: prevalence and impact on operative mortality. Ann Vasc Surg. 2002;16:679-84

5. Wolff T, Baykut D, Zerkowski HR, Stierli P, Gürke L. Combined abdominal aortic aneurysm repair and coronary artery bypass: presentation of 13 cases and review of the literature. Ann Vasc Surg. 2006;20:23-9. 